\title{
Sacramentos y teología de la liberación
}

\section{José M. Castillo, \\ Granada, España. \\ Centro de Refexión Teológica, San Salvador, El Salvador.}

Uno de los temas menos estudiados, hasta ahora, por la teología de la liberación es el que se refiere a la teologia de los sacramentos. En efecto, la teologla de la liberación ha producido una excelente cristología, una buena eclesiologia, una profunda espiritualidad, etc. Sin embargo, al menos por lo que respecta al tratado de sacramentis in genere, la producción teológica ha sido, hasta ahora, más bien reducida El reciente libro de Francisco Taborda, Sacramentos, praxis y fiesta, publicado en la colección "Cristianismo y Sociedad", presenta en su bibliograffa ${ }^{1}$ sólo dos útulos de teólogos de la liberación: el de Leonardo Boff, Sacramentos de la vida ${ }^{2}$ y el de Juan Luis Segundo, Teologla abierta. II. Dios - Sacramentos - Culpa ${ }^{3}$. Sin duda alguna, se han escrito otras cosas, quizá en artículos sueltos, quizá en algún libro publicado posteriormente al de Taborda. En wodo caso, queda en pie la afirmación que hice al principio: la teología de la liberación no ha elaborado una sacramentologia amplia y original.

Por eso, hoy hay preguntas muy fundamentales, sobre este asunto, que eslán sin responder. ¿cómo habría que enfocar la sacramentologia para que ésta fuera coherente con la liberación del pueblo? ¿Qué relación se debe establecer entre sacramentos y teología de la liberación? ¿Qué aporta la teología de la liberación a la sacramentología? ¿Cómo scría necesario orientar los sacramentos para que éstos sean efectivamente liberadores? Estas y otras preguntas por el estilo están aún por responder. De lo cual se sigue una consecuencia trágica: en una abundante mayoría de casos, los sacramentos siguen siendo más instrumentos de dominación que verdaderos agentes de liberación. He aquí una cuestión a la que la teologfa debe responder con urgencia.

\section{Posibles razones de esta situación}

¿Por qué la teología de la liberación se ha ocupado relativamente poco de la 
sacramentología?

No es difícil descubrir las razones que han podido influir en este estado de cosas. En primer lugar, todos sabemos perfectamente que la gran preocupación de la teologia de la liberación ha sido cambiar la sociedad, teniendo como objetivo la liberación integral del hombre y del pueblo. Ahora bien, desde este planteamiento, los sacramentos han sido vistos como menos eficaces para liberar al pueblo de sus múltiples esclaviudes y dependencias. A fin de cuentas, los sacramentos se han practicado como rituales mas o menos rutinarios, sin una relación muy directa con los movimientos liberadores.

Por otra parte, está la clásica y tópica división entre sacramentalización y evangelización. Pero es claro que la gran preocupación en América Latina ha sido y sigue siendo la evangelización. De ahi que, como muy bien ha dicho $F$. Taborda, se canta en diversos tonos la misma melodía: sacramentos y praxis historica, símbolos del reino y realización del reino, sacramentalizar y evangelizar, sacramenws y vida cristiana, religión y fe, Iglesia de sacristia e Iglesia comprometida, verticalismo y horizontalismot. En definitiva, se trata de comprender que los sacramentos no han sido vistos, en la teología de la liberación, como agentes de cambio y como medics de liberación.

Seguramente, en todo este asunto, ha influido decisivamente otro hecho que resulta eminentemente iluminador. A la gente sencilla del pueblo le interesan los sacramentales más que los sacramentos. De tal manera que los sacramentales han sido designados como los sacramentos de los pobres. En este sentido, ha escrito recientemente Víctor Codina: "no creo exagerado concluir que para el pueblo, es decir, para sectores sencillos, culturalmente ligados al mundo rural, económicamente débiles y pobres, los sacramentales son más valiosos que los sacramentos. Los sacramentales son los sacramentos de los pobres"s. $\mathrm{Y}$ asi parece que es efectivamente, al menos en muchos casos. Baste tener en cuenta el aprecio práctico que mucha gente hace de las bendiciones y las imágenes, del agua bendita, de la ceniza de cuaresma o de las palmas del domingo de ramos. Por eso, como indica el mismo Codina, "tanto pastoral como teologicamente habría que pasar de los sacramentales a los sacramentos, no al revés, del mismo modo que habría que afirmar que la Iglesia es sacramento de salvación desde la historia de las religiones, no al revés. Los sacramentales no son formas degradadas de sacramentalidad, sino que los sacramentos son la culminación de los sacramentales $^{\text {nt6 }}$.

El hecho es que los sacramentos interesan poco a grandes sectores de la población. Interesa más que todo el complejo mundo de la religiosidad popular: las imágenes y su veneración, los novenarios, las romerías, los exvotos y tantas otras cosas que rozan con lo mágico o lo supersticioso. Por eso se explica que la teología de la liberación se haya interesado abundantemente por la religiosidad popular, mientras que se ha preocupado menos de la sacramentología. 
Por otra parte, la religiosidad popular goza de una libertad y una espontaneidad que no se da en los sacramentos. Hablar de religiosidad popular es hablar de la expresión libre y connatural del pueblo, mientras que el sacramento está siempre sometido a un ritual establecido y controlado por la autoridad. Por eso, el pueblo se encuentra más a gusto en los actos de religiosidad popular que en las celebraciones de los sacramentos. De ahl que las expresiones de la religiosidad popular suelen ser masivas y multitudinarias, mientras que las celebraciones sacramentales son siempre más restringidas, son para menos gente. Esto explica que, en la religiosidad popular, se han visto unas posibilidades liberadoras que no se han descubierto en los sacramentos.

Pero hay más. Los sacramentos son, con frecuencia, utilizados como instrumentos de sometimiento y de dominación sobre el pueblo. Así, el bautismo ha sido utilizado como el sacramento por el que se le imponen al nifio, antes del uso de razón, las pesadas obligaciones que la Iglesia exige a sus miembros. La penitencia es de hecho el sacramento del dominio del clero sobre las conciencias de los fieles. La eucaristía, un buen procedimiento para controlar quiénes son asiduos a las prácticas eclesiásticas y quiénes no. El sacramento del orden es el instrumento por el que el aparato del poder eclesiástico domina y somete a los responsables de la instiución eclesiástica. Y el matrimonio, el medio por el que los clérigos se imponen a las familias y les urgen sus obligaciones. Por supuesto, sé que a nivel consciente las cosas no se plantean de esta manera. Pero no cabe duda que, en la práctica, funciona así, por más que este modo de hablar resulte chocante o incluso escandaloso para detemninadas personas.

De ahí la necesidad urgente de replantear la funcionalidad de los sacramentos en nuestra sociedad y en nuestra Iglesia. ¿Para qué han servido y de hecho siguen sirviendo los sacramentos? ¿Para ser agentes de liberación? ¿O para ser, más bien, instrumentos de dominación? Y no se piense sólo en lo que todo esto supone de dominación religiosa de la jerarqufa eclesiástica sobre los fieles. Hay algo que es más importante que todo eso. En la medida en que la institución eclesiástica se vincula y hasta se somete a los poderes de este mundo, sobre todo al poder polílico, en esa misma medida los sacramentos son instrumentos de sometimiento social, económico y político ante los poderes de este mundo.

Por todo esto, estoy profundamente convencido de que mientras la teologfa de la liberación no aborde en profundidad el tema de los sacramentos, habrá en ella una laguna muy fundamental. Porque en tanto en cuanto los sacramentos sigan funcionando como hasta ahora funcionan en la Iglesia, todas nuestras grandes palabras sobre la liberación serán voces en desierto sin eco ni respuesta.

\section{Los simbolos de la experiencia cristiana}

Muchas veces se ha dicho que los sacramentos son signos eficaces que nos 
comunican la gracia Esta definición, sin embargo, se queda corta y resulta insuficiente. Porque un signo es la unión de un significante y un significado. Pero de tal manera que el significado es siempre un concepto. Por ejemplo, en el lenguaje, cada palabra es un signo, porque en la palabra el significante (fonema), al unirse con el signficado (concepto), se forma o se configura el signo ${ }^{7}$. Pero esto nos viene a decir que el signo se sitía siempre a nivel lingillistico. $Y$ por lo tanto, a nivel conceptual.

Ahora bien, todos sabemos que en la vida hay experiencias que no se pueden comunicar a nivel lingúístico o conceptual, sino que se sitúan a un nivel más profundo, el nivel simbólico. Ast, en el complejo mundo de las relaciones humanas, en el psicoanálisis y en la historia comparada de las religiones, aparecen con frecuencia experiencias que resultan sencillamente inefables. Porque no se pueden expresar mediante signos. De ahi la necesidad de los símbolos, que son la expresión de nuestras experiencias más profundas.

De ahr que todo símbolo se compone de dos elementos: la experiencia, que adentra sus raices en el inconsciente de la persona; y la expresión extema de esa experiencia Si falta uno de estos dos elementos, no hay símbolo".

Por otra parte, a partir de lo diclıo, se comprende cuál es la función del símbolo. Esta función es triple: en primer lugar, el simbolo asume la experiencia profunda del inconsciente de la persona. En segundo lugar, el símbolo traduce esa experiencia al nivel de la conciencia. En tercer lugar, el símbolo expresa y comunica la experiencia en cuestión. Por ejemplo, en las relaciones humanas, el afecto se expresa mediante la mirada, el abrazo, la caricia y el beso. Tales expresiones son simbolicas, porque asumen la experiencia profunda de la persona, la traducen a nivel de la conciencia y la expresan o comunican.

Ahora bien, la fe cristiana comporta experiencias muy profundas, que no se pueden comunicar sólo mediante signos, a nivel lingúístico. La experiencia del amor, de la esperanza, de la libertad, etc. adentran sus ralces en el inconsciente de la persona $Y$ por eso, sólo se pueden asumir y expresar adecuadamente mediante símbolos. Tales símbolos son nuestros sacramentos.

Pero conviene tener presente que, con relativa frecuencia, los símbolos tienen el peligro de degenerar en meros ritos, vacíos de contenido. Esto ocurre cuando la experiencia de vida muerte y desaparece, pero de tal manera que el gesto externo se mantiene y perdura. Entonces, ese gesto no pasa de ser un rito rutinario y funcional, carente de vida. En el complejo mundo de las relaciones humanas, muchas personas se dan la mano, se abrazan o incluso se besan, pero de tal manera que eso no corresponde a ninguna experiencia interna de afecto o de amor. Se mantiene el gesto externo como un mero ritual, pero sin correspondencia con la realidad que vive la persona.

Lo mismo ocurre, lantas y lantas veces, en la vida de los cristianos. Se 
reciben sacramentos, pero de tal manera que son, en realidad, meros ritos, que no corresponden a la experiencia interna que viven las personas. Tales ritos, aunque sean vólidos y líciros, no son los sacramentos auténticos que Cristo instituyó. Por el contrario, cuando exisle una profunda correspondencia entre el rito externo y la experiencia interna, que vive la persona, entonces, tenemos el sacramento auténtico. Por eso he dicho que los sacramentos son los símbolos de la experiencia cristiana.

\section{La experiencia de la libertad}

Se suele decir que la experiencia crisliana esencial es la experiencia del amor: el amor de Dios y el amor a Dios; el amor del prójimo y el amor al prójino. $\mathrm{Y}$ asl es, efectivamente. Para convencerse de ello basta leer los evangelios y en general todo el Nuevo Testamento.

Sin embargo, al decir esto no hemos tocado el fondo de la cuestión. Porque según el discurso de la institución, tanto religiosa como política, el amor se expresa y se traduce en sometimiento, en obediencia. De tal manera que tanto se ama cuanto se obedece. Así comprendemos que la obra maestra del poder consiste en hacerse amar: amar a la Iglesia-instiución-jerárquica, amar a la patria, amar a los demás, consiste esencialmente en someterse, en obedecer?. Someterse y obedecer a leyes concretas, a personas concretas, a instituciones concretas. Así es como se propaga la sumisión y los súbditos rinden al poder y a la autoridad un amor $\sin$ fin $^{10}$.

El evangelio, sin embargo, plantea las cosas de mancra muy distinta. Porque, para Jesús, la manifestación esencial del amor no es el sometimiento, sino la libertad. Por eso, Jesús quebranta insistentemente el sábado, no hace caso de las normas de pureza ritual (cf. Mc 7, 1-23) y entra en conflicto con los fariseos, los letrados y los sumos sacerdotes. El enfrentamiento de Jesús con la institución religiosa de su tiempo es la demostración más patente de que la expresión esencial del amor no es el sometimiento, sino la libertad. Concretamente, la libertad frente a las patologias que por lo general son inherentes a las instituciones, incluidas las instituciones religiosas.

La patología de las instituciones consiste en que éstas, con demasiada frecuencia, anteponen sus intereses a sus fines. De donde se produce la perversión radical. Por ejemplo, una fundación, que está montada para ayudar a la gente más necesitada, un buen día descubre que se gasta mucho más dinero en pagar a sus empleados, en mantener sus edificios y en organizar sus campañas de propaganda, que en ayudar efectivamente a los pobres, único fin para el que fue fundada. He aquí la patología institucional en toda su crudeza.

Pues bien, lo mismo puede ocurrir en las iglesias. Ellas estón instituidas para evangelizar. Pero, con relativa frecuencia, ponen más interés y gastan más 
energias en promover a sus dirigentes y en defender el poder y el prestigio de la institución, que en transmitir el evangelio. E incluso no raras veces hacen cosas que van directamente en contra del mismo evangelio. Evidentemente, en tales circunstancias, la expresión del amor no es ni puede ser el sometimiento, sino la libertad liberadora, que se expresará en protesta profética e incluso en rebeldia frente a la institución.

Esta patología se produce sobre todo en las instituciones políticas y económicas. Tales instiluciones, en efecto, con una abrumadora frecuencia, promueven y defienden más los intereses de los poderosos y dirigentes, que el servicio al pueblo, sobre todo al pueblo humilde y marginado. $Y$ aquí es donde hay que hablar más de pecado estructural que de pecados personales. Dicho de otra manera, no discutiremos ahora la buena o mala voluntad de los dirigentes. El problema está en que las estructuras socio-económicas y socio-políticas están organizadas de tal manera que, por sus mismas reglas de juego, inevitablemente favorecen y apoyan descaradamente a los potentados de este mundo, mientras que a los pobres los dejan con las manos vacias. Exactamente al revés de lo que anuncia el Magnificat.

Ahora bien, estando asf las cosas, se comprende cómo y hasta qué punto la experiencia cristiana esencial tiene que ser la experiencia de la liberiad liberadora. Es decir, el problema no está en la libertad como experiencia intimista y autocomplaciente, sino en la libertad como protesta profética y rebeldía frente a los procesos patológicos de las instituciones, que desembocan en la exaltación de los poderosos y en la humillación de los pobres y marginados de este mundo.

Decir que la experiencia cristiana esencial es el amor es verdad. Pero puede resular una verdad a medias. Porque si ese amor no se traduce en lucha por la libcración del pueblo oprimido, semejante amor pucde resultar una manera bastante eficaz de alienación, es decrr, de falsa conciencia, que solo sirve para autocontentarse y autoengafiarse.

En delinitiva, se urata de comprender que la experiencia cristiana esencial es la experiencia de la libertad. Y es esa experiencia la que el sacramento tiene que asumir, traducir a nivel de la conciencia, y finalmente, expresar y comunicar a los demás, a los individuos y a la sociedad.

Ahora se comprende por qué los sacramentos no han sido objeto de especial estudio por parte de la teología de la liberación. Tal como se celebran los sacramentos en la Iglesia, de hecho, actúan más como mantenedores de la situación establecida que como agentes de cambio. Porque no se da una adecuada correspondencia entre la experiencia de la liberación y los rituales tal como se celebran en concreto. De hecho, es mucha la gente que se accrca a recibir los sacramentos sin tener experiencia alguna de liberación. Es más, resulta relalivamente frecuente que reciban los sacramentos los agentes de la opresión del 
pueblo, los explotadores y hasta los tiranos. Evidentemente, en tales circunstancias, resulta prácticamente imposible que el sacramento sea agente de liberación. Estando asl las cosas, parece que los sacramentales y la religiosidad popular en general se pueden encauzar más fácilmente por el camino de b liberación que los mismos sacramentos.

\section{Agentes de liberación}

¿Cómo serfa necesario celebrar los sacramentos para que éstos sean efectivamente los grandes agentes de la liberación del pueblo?

Para responder a esta cuestión, lo primero que sería necesario aclarar es quién puede participar en la celebración. Lo normal es que en la celebración de los sacramentos participe todo el que quiere. Porque, tal como se celebran, los sacramentos son servicios religiosos puestos a disposición del público. Por lo tanto, lo mismo los ricos que los pobres, lo misno los explotadores que los explotados, to mismo los sefores que los esclavos, todo el mundo indistintamente toma parte en el sacramento. Ahora bien, mientras las cosas sigan así, será prácticamente imposible que los sacramentos actúen como agentes de liberación. Porque, en la práctica, servirán para tranquilizar las conciencias de los opresores y legitimar la simación establecida.

En la Iglesia primitiva, durante los primeros siete siglos del cristianismo, existió la penitencia pública cuya finalidad era impedir que se acercasen a participar en la eucaristía los pecadores públicos y escandalosos. De esta manera, los causantes de la injusticia y, en general, los opresores de los pobres quedaban eliminados de la celebración sacramental. Y el sacramento actuaba como agente de liberación. En este sentido, sabemos que los pecados que excluían al creyente de la eucarisúa eran los pecados escandalosos ${ }^{11}$, entre los que se enumeraban de manera especial los pecados contra el prójimo, no sólo el homicidio y el robo, sino además la pleonexía (avaricia) y la adikí (injusticia) ${ }^{12}$. Seguramente, el caso más famoso, en este orden de cosas, es el de san Ambrosio, cuando el emperador Teodosio cometió la masacre de TesaIónica's . La reacción de Ambrosio consistió, ni más ni menos, que en una carta dirigida al emperador en la que le comunicaba que no celebraría delante de él la eucaristía si se atrevía a asistir. La eucaristía no podía estar en connivencia con los dictadores ni con los tiranos. Ni podía tolerar el atropello del hombre hacia su hermano.

Soy consciente de las dificultades que hoy representaría el intento para restaurar la práctica de la penitencia pública. Pero pienso que es sencillamente escandaloso dar la comunión a los dictadores, a los tiranos y a los violadores manifiestos de los derechos humanos. Por lo demás, creo que no seria exigir demasiado si pedimos que las conferencias episcopales establezcan unas condiciones mínimas de posiblidad para la celebración de los sacramentos. So- 
lamente ast podrlamos aspirar a tener una Iglesia santa, verdadero agente de liberación en la sociedad.

Cuando la Iglesia se dedica a publicar documentos y a pronunciar palabras grandilocuentes sobre la liberación (y ojalá que siempre hiciera, por lo menos eso), algo hace por esa causa. Pero en realidad eso es relativamente poco. No olvidemos que la experiencia cristiana esencial es la experiencia de la liberación. Y esa experiencia, cuando existe de verdad, se traduce en expresión simbólica, es decir, en expresión sacramental. Por eso, en la acción pastoral, el empeño mayor se debe concentrar en hacer vivir a los fieles la experiencia de la liberación. Porque de ahí se seguirá, como la cosa más natural del mundo, la celebración sacramental liberadora con todo su vigor y toda su fuerza.

Pero es claro, para que la celebración sea verdaderamente tal, se requiere que exista una auténtica correspondencia entre la experiencia interna de la liberación y su expresión ritual y externa. Por to tanto, las oraciones, los cantos, los gestos simbolicos deben expresar la liberación de los pobres y sus auténticas aspiraciones. Lo cual quiere decir que la celebración tiene que ser claramente parcial. Parcial a favor de los pobres y enormemente crílica con los ricos y poderosos de este mundo. Hay que acabar con la imparcialidad de la linurgia. En la práctica, nuestras liturgias actuales son la expresión más perfecta del descompromiso con las situaciones sociales, económicas y políticas. Sería necesario acabar cuanto antes con este estado de $\operatorname{cosas}^{14}$. Aunque ello resultara subversivo y revolucionario. Precisamente eso es lo que se pretende, una celebración culual en la que los pobres encuentren recogidas y formuladas sus aspiraciones. Y en la que precesisamente por eso los ricos y los opresores se sientan profundamente incómodos y en un radical desacuerdo.

\section{Conclusiones}

Se trata ahora de recoger, en una breve síntesis, las principales aportaciones del presente trabajo.

(1) Urge elaborar una sacramentologia de la liberación. En este punto existe una verdadera laguna en la teología de la liberación. Mientras este asunto no se aborde en profundidad, la teología de la liberación será una teologia incompleta.

(2) El punto de partida de esta leología, bien podría ser la teoría del símbolo como expresión de nuestras experiencias más profundas. Por supuesto, sé muy bien que las teorfas sobre el símbolo son múltiples e incluso muy diversas. Pero lo que aquí nos interesa es la realidad profunda que queremos expresar al hablar del símbolo. Y pienso que en eso sí puede haber un acuerdo básico.

(3) La cuestión clave eslá en comprender que la experiencia cristiana esencial es la experiencia de la liberación. Y que esa experiencia, como coda 
experiencia profunda, sólo puede expresarse adecuadamente mediante el gesto simb6lico.

(4) Para que el punto anterior sea posible, es enteramente necesario confeccionar una liturgia que corresponda a la experiencia liberadora; de tal manera que los cantos, las oraciones y los símbolos en general sean verdaderamente la expresión de las aspiraciones de los pobres y marginados de este mundo.

\section{Notas}

1. F. Taborda, Sacramensos, praxis y fiesta, Medrid, 1987, 187.

2. L. Boff, Sacramentos de la vida, Bilbro, 1977.

3. J. L. Segundo, Teologla abierta. II. Dios-Sacramensos-Culpa, Madrid, 1983, 211 343. El P. Viclor Codina publica un arúculo importante sobre los sactamentos en la ceología de la liberación en la obra en colaboración Concepias fundamentales de teologia de la liberación, dirigida por Ignacio Ellacuría y Jon Sobnino.

4. F. Taborda, o. c., 12.

5. V. Codina, "Sactamenteles, sactamentos de los pobres", Revista Latinoamericana de Teologia, VII (1990) 209.

6. V. Codina, o. c., 214.

7. Para el concepto de signo, cf. J. M. Castillo, Súmbolos de liberiad, Salamanca, 1981, 169-171. Cf. tambien G. Mounin, Ferdinand de Saussure, Paris, 1968; J. Lyons, Insroducción en la lingǘstica teórica, Barcelona, 1975; A. J. Greimas, Sémantique structurale, Paris, 1966.

8. Para el concepto de símbolo, cf. J. Spleh, "Símbolo" en Sacramentum Mundi, VI, Barcelona, 1976, 359; E. Leach, Culsura y comunicación. La Logica de la conexión de los símbolos, Madrid, 1978, 133-137; D. Sperber. Le symbolisme en général, París 1974, 161-163; F. Manresa, El concepto de símbolo en la teología de Paul Tillich, Sant Cugah 1977, 235-258; K. Rahner, "Para una teología del símbolo", en Escrisos de teologia, IV, Madrid, 1962, 285-287; W. Heinen, Bild-Wort-Symbol. Versuch einer kritischen Theorie sakramentaler Praxis, Dissseldorf, 1974; P. Ricoeur, "Parole et symbole", en la obra dirigida por J. E. Menard, Le Symbole, Strasburg. 1975, 143ss; Id. La mélaphore vive, París, 1975, 13-61; J. M. Cascillo, Simbolos de libertad, 171-179.

9. Cf. P. Legendre, L'amour du censew, Paris, 1974, 5. Sobre este plunto cf. C. Domínguez, "Mea culpa, mea culpa, mea maxima culpa", Proyección 26 (1979) 119 133.

10. Cf. P. Legendre, Jopuir du pouvoir. Traité de la bureau-cratie patriote, París, 1976, 13.

11. Cf. J. Turmel, Histoire des Dogmes, VI, Paris, 1936, 114,

12. Para este punto véase C. Vogel,"El pecado y la penitencia", en B. Haering y otros, Pastoral del pecado, Estella, 1966, 219-221.

13. Este asunto ha sido estudiado por J. R. Palanque, Sains Ambroise et l'Empire Romain, Paris, 1933, 200-244. También por H. von Campenhausen, Ambrosius van Milan als Kirchenpolitiker, Berlín-Leipzig, 1929, 212-240. Ha resumido bien el problema H. Rahner, Kirche und Staat im frühen Christentum, Minchen, 1961, 97. 
112. La posture tajente de Ambrosio nos consta por une carta suya Sus palabras son terminantes: Offerre non audeo sacrificiwn, si volueris assistere, Epist 51. PL 16, 1160.

14. Con todo, se debe tener en cuenta que, en bastentes comunidades eclesiales de base, ya se presenten oraciones y se hacen planteamientos en los que se pone de marifiesto la parcialidad de Dios en favor de los pobres. 